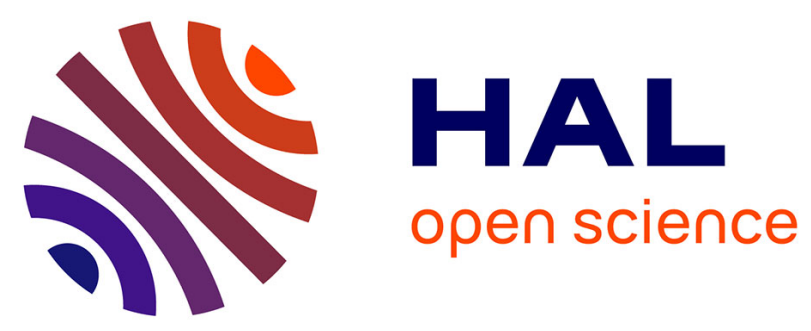

\title{
North-south asymmetries in the thermosphere during the Last Maximum of the solar cycle
}

\author{
F. Barlier, Pierre Bauer, C. Jaeck, Gérard Thuillier, G. Kockarts
}

\section{To cite this version:}

F. Barlier, Pierre Bauer, C. Jaeck, Gérard Thuillier, G. Kockarts. North-south asymmetries in the thermosphere during the Last Maximum of the solar cycle. Journal of Geophysical Research Space Physics, 1974, 79, pp. 5273-5285. 10.1029/JA079i034p05273 . hal-01627389

\section{HAL Id: hal-01627389 \\ https://hal.science/hal-01627389}

Submitted on 1 Nov 2017

HAL is a multi-disciplinary open access archive for the deposit and dissemination of scientific research documents, whether they are published or not. The documents may come from teaching and research institutions in France or abroad, or from public or private research centers.
L'archive ouverte pluridisciplinaire HAL, est destinée au dépôt et à la diffusion de documents scientifiques de niveau recherche, publiés ou non, émanant des établissements d'enseignement et de recherche français ou étrangers, des laboratoires publics ou privés. 


\title{
North-South Asymmetries in the Thermosphere During the Last Maximum of the Solar Cycle
}

\author{
F. Barlier, ${ }^{1}$ P. Bauer, ${ }^{2}$ C. Jaeck, ${ }^{1}$ G. Thuillier,${ }^{3}$ and G. Kockarts ${ }^{4}$
}

\begin{abstract}
A large volume of data (temperatures, densities, concentrations, winds, etc.) has been accumulated showing that in addition to seasonal changes in the thermosphere, annual variations are present and have a component that is a function of latitude. It appears that the helium concentrations have much larger variations in the southern hemisphere than in the northern hemisphere; the same holds true for the exospheric temperatures deduced from Ogo 6 data. Similarly, satellite drag data in the 250 - to $400-\mathrm{km}$ range indicate that the bulge of density tends to stay over the southern hemisphere, whereas winds deduced from Ogo 4 and 6 data show a tendency to blow northward across the equator. If part of the explanation of these asymmetries can be found in a latitude independent component induced by the changing sun-earth distance between solstices (Volland et al., 1972; Ching and Chiu, 1972, 1973), the fact that an asymmetry is still present at the equinoxes suggests that this is not the sole cause: more energy seems to be available for the thermosphere in the southern hemisphere during the equinoxes; this may be the result of an asymmetry in the geomagnetic field or an asymmetrical dissipation of tidal waves induced by an asymmetrical worldwide ozone distribution.
\end{abstract}

An asymmetry between the two hemispheres became apparent very early in the study of the semiannual variations of the thermospheric density. The density minimum is systematically deeper in July than in January [Paetzold and Zschörner, 1961; Roemer, 1963; Jacchia, 1965]. For the same local season the mean density is not the same in both hemispheres. New evidence of asymmetries in the thermospheric parameters between the two hemispheres has recently been pointed out by Keating et al. [1973], Barlier et al. [1973], and Blamont and Luton [1972]. A major feature of these asymmetries is the nonpermutability of the values of thermospheric parameters of the northern hemisphere for a solstice with those of the southern hemisphere for the other solstice. Furthermore, systematic differences exist between the two hemispheres at the time of equinox, and these differences have the same sign for spring and fall conditions. Neutral temperature, density, concentration, and wind data have been gathered in order to study their hemispherical asymmetries.

The first part of the present paper is devoted to an analysis of experimental data characterized by asymmetrical properties during the last maximum of solar activity. The second part is designed to show that most of the observed asymmetries can be considered as resulting from a unique cause, namely, an asymmetrical thermospheric heating of the two hemispheres for identical solar conditions. Finally, possible energetic mechanisms are considered, namely, heating linked to geomagnetic activity and heating due to dissipation of tidal waves.

\section{Data Analysis}

Thermospheric temperatures. Temperatures near $270 \mathrm{~km}$ have been deduced from Fabry-Perot interferometric measurements of the $6300-\AA$ red line on board the Ogo 6 satellite [Blamont and Luton. 1971]. Reliable data have been obtained during the daytime over the period June 1969 to

\footnotetext{
${ }^{1}$ Groupe'de Recherche de Géodésie Spatiale, Centre d'Etudes et de Recherches Géodynamiques et Astronomiques, Grasse, France.

${ }^{2}$ Centre National d'Etudes des Télécommunications, Issy-lesMoulineaux, France.

${ }^{3}$ Centre National de la Recherche Scientifique, Service d'Aéronomie, Verrières le Buisson, France.

'Institut d'Aéronomie Spatiale de Belgique, Brussels. Belgium.

Copyright (C) 1974 by the American Geophysical Union.
}

August 1970. The orbital characteristics were such that 24 hours of local time was covered over a period of 90 days.

The data available for this study were limited to low and middle latitudes (up to $60^{\circ}$ ). These data are in a sense a natural choice, since a previous study [Blamont and Luton, 1972] has shown that the high-latitude behavior is largely determined by geomagnetic activity. The data were averaged over latitudinal strips $30^{\circ}$ wide.

Figure 1 gives variations of the temperature differences between northern and southern mid-latitudes $\left(45^{\circ} \mathrm{N}-45^{\circ} \mathrm{S}\right.$ and $25^{\circ} \mathrm{N}-25^{\circ} \mathrm{S}$ ) as a function of the calendar day. A 90-day running mean of the data was performed to eliminate diurnal variations. The reason for considering the difference in temperature for corresponding geographical latitudes in the two hemispheres is to eliminate the effects of solar flux and geomagnetic activity. The observed residuals should therefore characterize essentially the seasonal variations. Two different features can be seen in Figure 1:

1. For $25^{\circ}$ latitude the temperature difference is practically always negative or equal to zero; i.e., the southern hemisphere in this latitude range appears generally to be warmer than the northern hemisphere. This is a clear indication of the presence of an asymmetry of the temperature behavior in these two regions, since a purely seasonal effect would tend to give an oscillation centered around zero. It must be noted that at equinox the southern temperature is still significantly higher than the northern one: August 26, 1969, to April 1, 1970, is a period of continuously higher southern temperatures.

2. The situation is different at $45^{\circ}$, where a seasonal effect can be clearly seen. It will be noticed, however, that equal temperatures are observed around September 16, 1969, and March 26, 1970, which tends to enhance the period when the southern hemisphere is warmer: the temperature difference seems to be larger for the December solstice than for the June solstice. Although the seasonal variation dominates at $45^{\circ}$, it is still possible to detect the asymmetry noted for $25^{\circ}$.

In order to ascertain the reality of the effect it is useful to look at the variation of the 80-day mean solar flux over the period of interest (Figure 2). Rather small variations $( \pm 7 \%)$ around the mean value are observed, and their residual effect on the temperature differences should be very small.

A comparison has been made with Waldteufel's [1971] model of temperature based on incoherent scatter data 

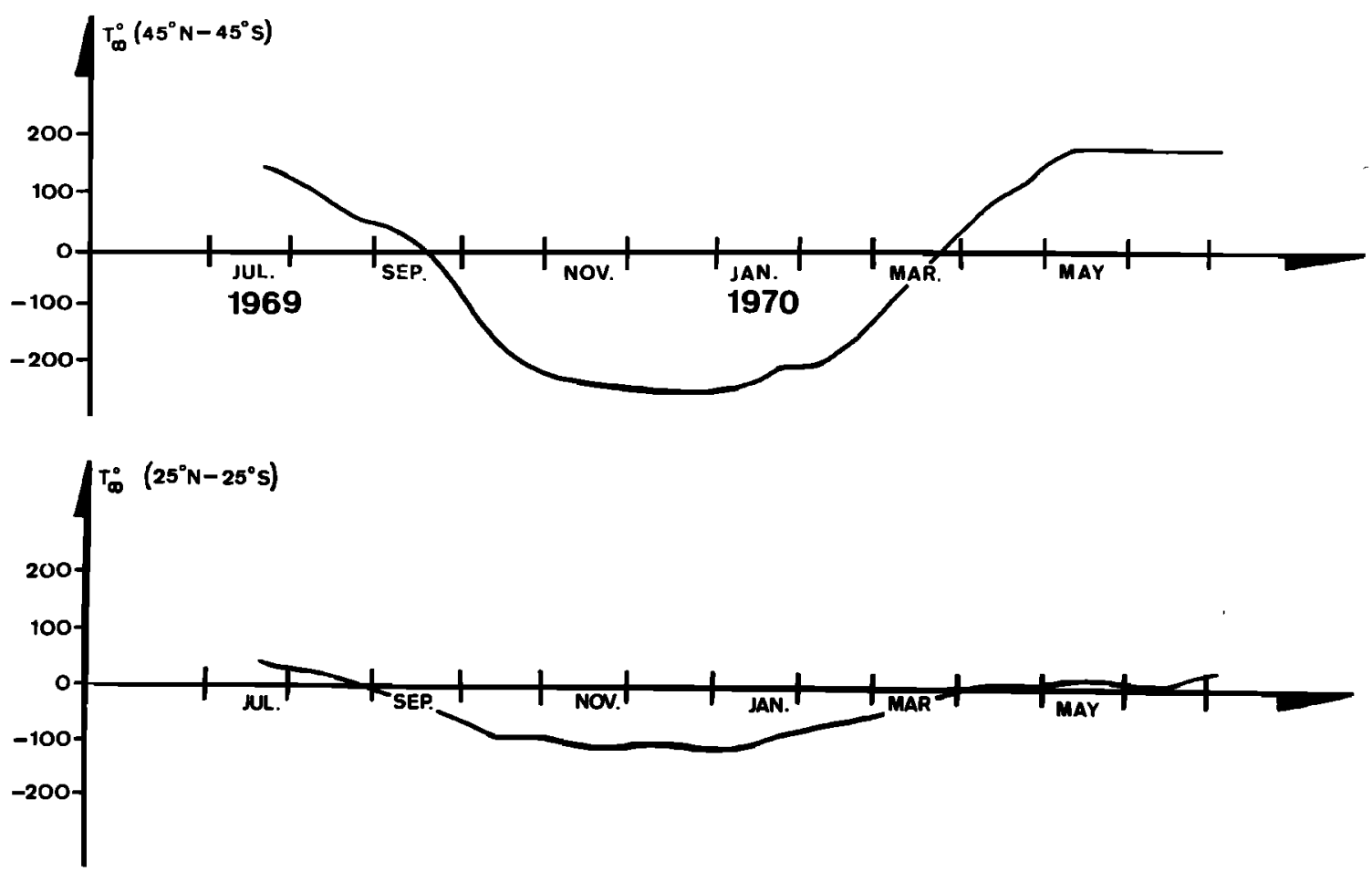

Fig. 1. Difference between northern hemisphere and southern hemisphere temperatures deduced from Ogo 6 measurements averaged over one revolution of the node for the zone of geographical latitudes centered on $\pm 45^{\circ}$ and $\pm 25^{\circ}$.

gathered at Arecibo $\left(18^{\circ} \mathrm{N}\right)$ and St. Santin $\left(45^{\circ} \mathrm{N}\right)$. The ratio of the observed temperature $T_{0 \text { go } 6}$ to the value given by this temperature model, $T_{\mathrm{wal}}$, is plotted in Figure 3 as a function of time for three latitudinal regions. Our purpose here is not to discuss the different details, but the main feature must be pointed out. Although no significant trend seems to be present in the behavior of the temperature ratio at $45^{\circ} \mathrm{N}$, the equatorial, and particularly the southern, data indicate that the observed temperatures are lower than the model values in July and August and higher between September and February.

Since Waldteufel's model is based only on temperature observations made in the northern hemisphere, it is normal to find a rough agreement in the northern hemisphere. However, the systematic effect observed at $45^{\circ} \mathrm{S}$, when it is taken into account that the model is symmetrical by construction for the two hemispheres, indicates that the amplitude of the winter to summer variation in the south is larger than that in the north.

To a lesser extent the same feature is observed at the equator, and this shows that an annual, rather than a seasonal, effect is involved. This annual effect is similar to the annual component of the 'semiannual variation' deduced by Jacchia [1971a] from an analysis of satellite drag data, and it constitutes an asymmetry in the thermospheric behavior.

Waldteufel's model can be adjusted to the Ogo 6 temperature data by varying only the 'seasonal' coefficient $C_{\mathrm{a}}$ for each range of latitudes considered. In this way, annual effects may appear as seasonal ones. The results are presented together in Figure 4. If only seasonal variations were present, positive values would be observed in the north, and negative values in the south. It appears, however, that the reversal occurs near $30^{\circ} \mathrm{N}$ instead of near the equator. The absolute value is much larger at $45^{\circ} \mathrm{S}$ than at $45^{\circ} \mathrm{N}$; this confirms that an annual effect exists. This annual effect is in phase with the seasonal effect in the south and is out of phase with that in the north. The region where the coefficient $C_{3}$ vanishes is shifted northward.

The nature of the asymmetry is further established by the latitudinal variation of the temperature for a given local time. Figure 5 shows the Ogo 6 temperatures versus latitude for different solstices and equinoxes and for local time varying

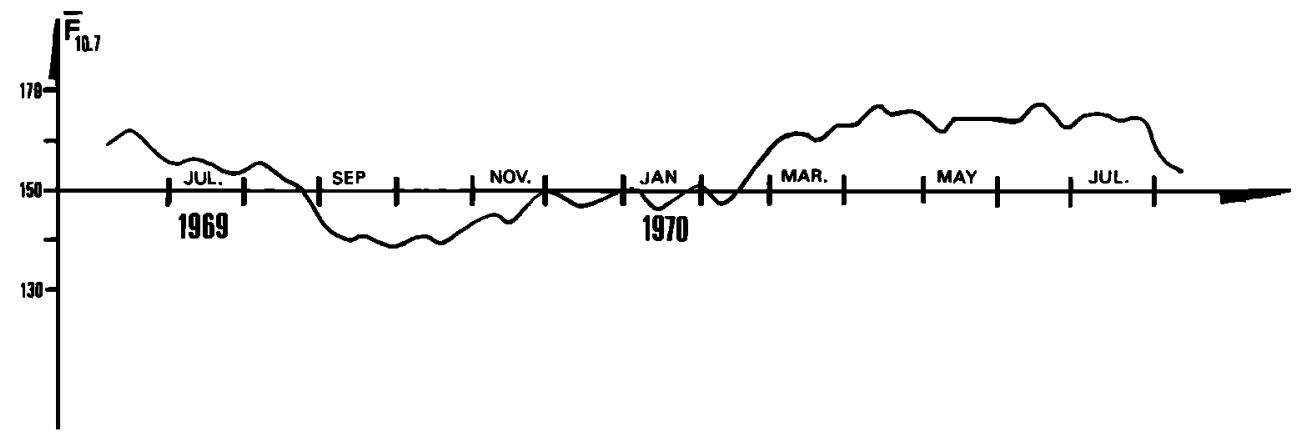

Fig. 2. Mean solar flux over the perıod of Ogo 6 measurements. 

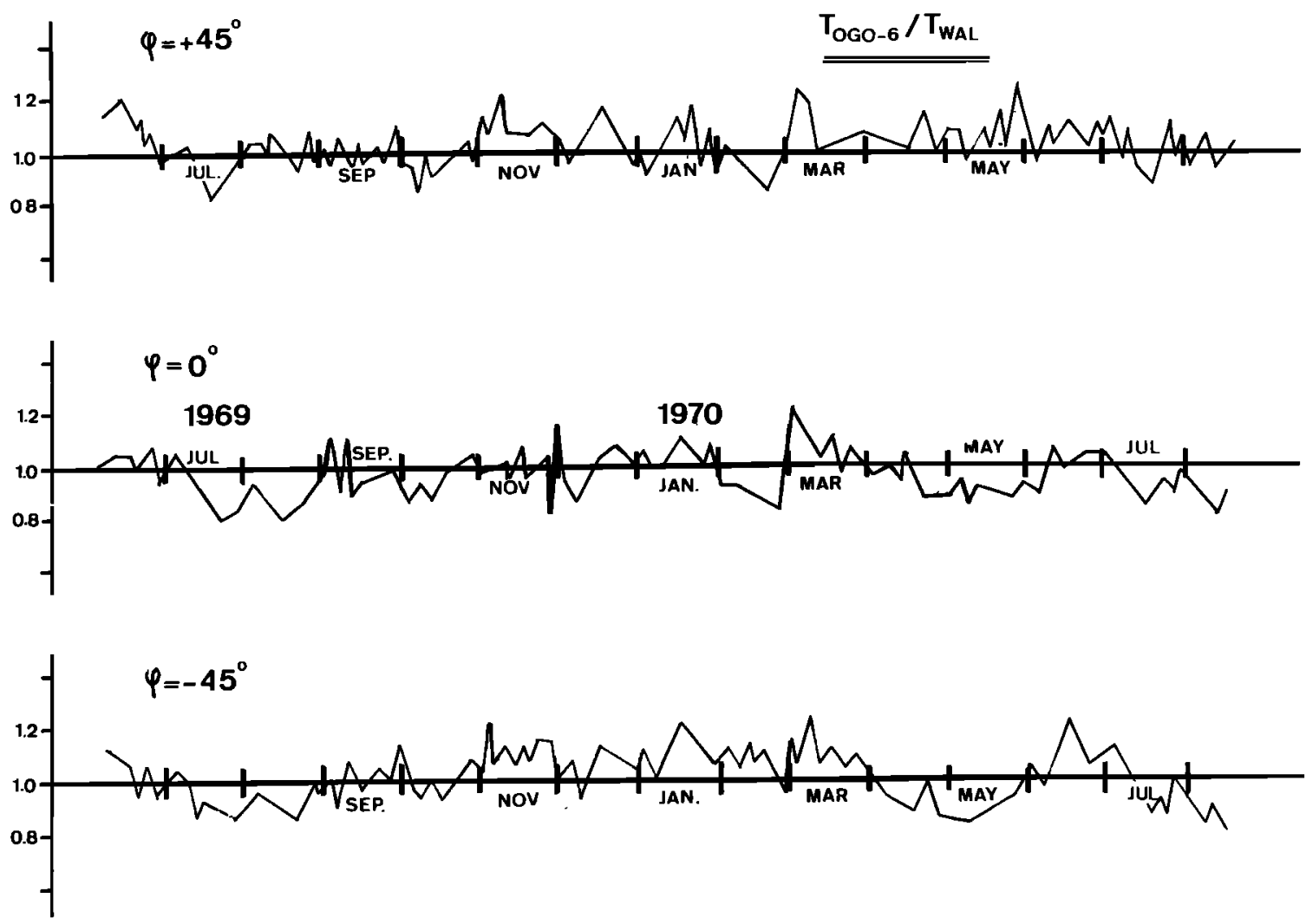

Fig. 3. Ratio of the observed temperatures $T_{\mathbf{O g o s}_{6}}$ and the temperatures obtained by using the Waldteufel model, $T_{\text {wal }}$.

between 1000 and 1700 hours. The data were, however, normalized to a $10.7-\mathrm{cm}$ solar flux of $150 \times 10^{-22} \mathrm{~W} \mathrm{~m}^{-2} \mathrm{~Hz}^{-1}$ and a geomagnetic activity corresponding to a mean $K p$ of 2 by use of the Jacchia 1971 model formulation [Jacchia, 1971b]. The solstice data indicate that the amplitude of the variation between the June and the December solstice is much larger in the south than in the north. The global average temperature is therefore higher in December than in June. This kind of asymmetry is also observed with the equinox data, which indicate that irrespective of the equinox considered, the temperature tends to be higher in the south.

Concentrations and total densities. The exospheric helium concentrations were deduced by Keating et al. [1973] from drag data of Explorer 9, 19, 24, and 39 between 1961 and 1971.

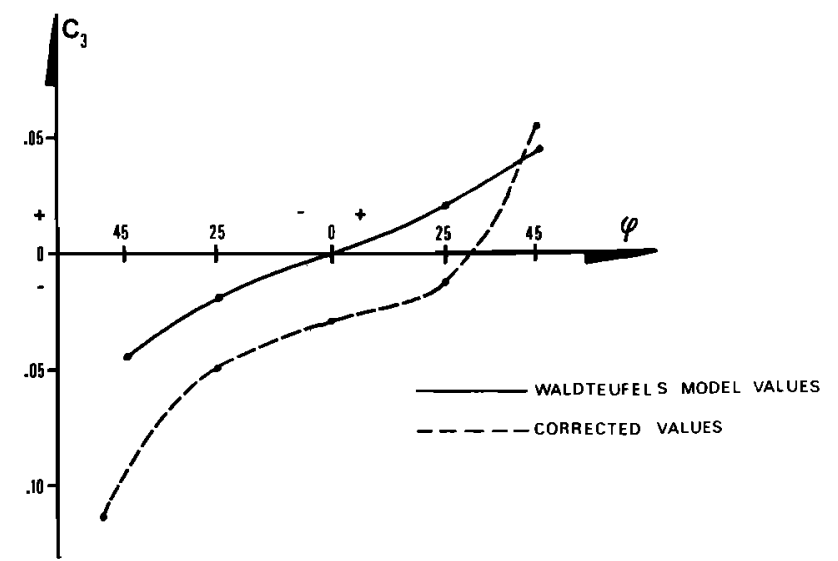

Fig. 4. Seasonal coefficient $C_{3}$ of the Waldteufel temperature model as a function of latitude, and adjusted values with Ogo 6 measurements.
By taking advantage of the complementarity of the orbits of these satellites Keating et al. [1973] evaluated the helium seasonal variation in the northern and southern hemispheres. Such a statistical analysis is, however, not available from the mass spectrometric data presented by Hedin et al. [1974].

The asymmetrical behavior of helium deduced by Keating et al. [1973] is presented in Figure 6. Although the helium concentration generally seems to be higher in the north than in the south, it appears that the most significant feature is a much larger seasonal variation in the south than in the north, the net result being equivalent concentrations for local winter in the north and the south and much lower concentrations for the southern summer than for the northern summer. This kind of asymmetry is not detectable in the Ogo 6 data [Hedin et al., 1974]: the measurements can be made only when the satellite is near perigee, and therefore it is impossible to observe densities in the southern and northern hemispheres simultaneously.

Satellite drag observations compiled by Barlier et al. [1973] and Jaeck-Berger [1973] have been used in several ways. In a first step a statistical treatment of drag data covering the last solar maximum (1967-1970) was performed around $280 \mathrm{~km}$. Each observation for a given latitude and local time was normalized to the worldwide minimum density predicted on the basis of the Jacchia 1971 model for the same conditions (solar flux, magnetic activity, and time of the year). The ratios of the observed densities to the computed minimum densities were then gathered into maps in Figure 7 corresponding to solstices and equinoxes.

It is well known [Jacchia, 197lb] that the latitude of the submaximum density point undergoes a migration correlated with the declination of the sun. However, if the latitude of the maximum is clearly in the south during the December solstice, it tends to stay close to the equator during the June solstice. The 

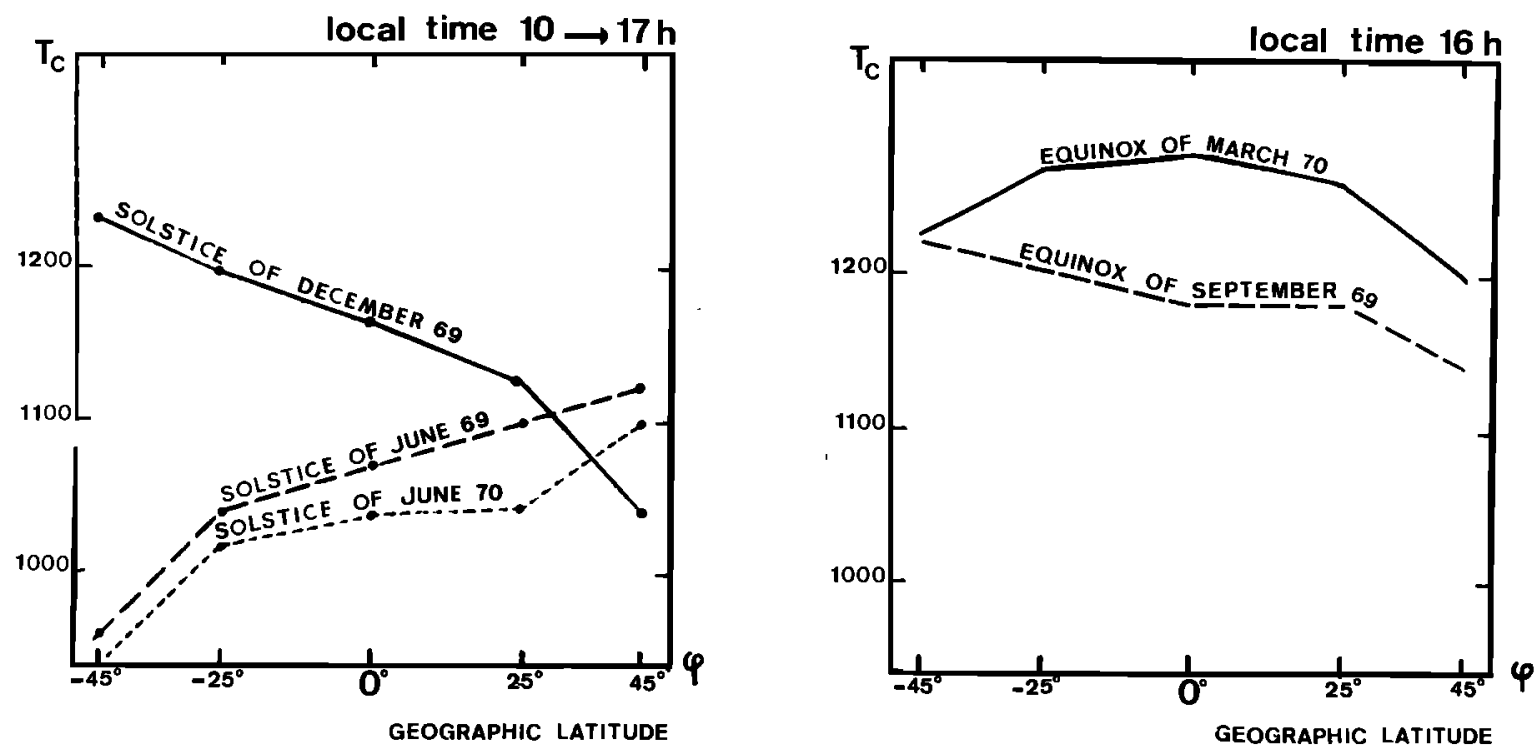

Fig. 5. Means for five zones of geographical latitude of observed temperatures corrected for the solar flux and geomagnetic activity by the Jacchia 1971 model for (left) 90 days around the solstices and (right) a few days around the equinoxes.

minimum of the June solstice is much more elongated than that of the December solstice. During the December solstice, density gradients across the equator are present during the second part of the night; during the June solstice this is not true.

The north-south asymmetry is not a phenomenon limited to solstices, since an asymmetry is still present at the equinox when the solar illumination of both hemispheres is the same (Figure 7). The density is generally higher in the south than in the north: indeed, on the one hand, the density maximum stays in the southern hemisphere, whereas, on the other, there are two density minimums (one in each hemisphere), the one in the northern hemisphere being more pronounced than the one in the southern hemisphere. This fact has also been demonstrated by Harper [1971].

The densities at $480 \mathrm{~km}$ deduced by Barlier et al. [1973] from satellite drag data for the period covering the Ogo 6 obser-

$$
\text { EXPLORER } \quad \text { g } 192439 \quad(2 / 61-9 / 71)
$$

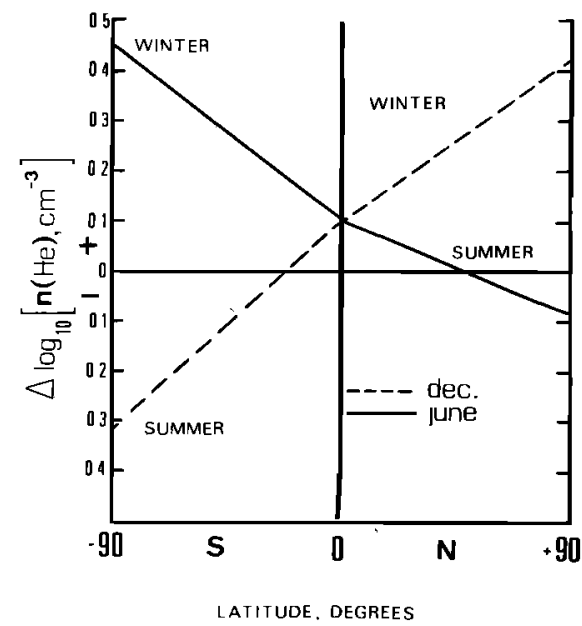

Fig. 6. Seasonal variation of exospheric helium in the northern and southern hemispheres based on all available helium drag data (Explorer 9, 19, 24, and 39) from February 1961 through September 1971 evaluated in separate $10^{\circ}$ latitude increments [Keating et al., 1973]. vations have also been averaged over 90 days for the purpose of comparison with the temperatures. The density differences between conjugate geographical latitudes have been plotted in Figure 8. The densities in the northern hemisphere appear to be systematically smaller than or equal to the corresponding values in the southern hemisphere. This is observed at $25^{\circ}$ as well as at $45^{\circ}$. Such behavior is consistent with generally higher temperatures observed over the south.

In order to separate thermal expansion effects from changes in the lower boundary densities the $480-\mathrm{km}$ densities, which correspond to atomic oxygen, have been reduced to $200 \mathrm{~km}$ by making use of the temperature determined by Ogo 6 and by assuming that diffusive equilibrium prevails in this altitude range. The choice of $200 \mathrm{~km}$ rather than a lower height is due to the uncertainties concerning both the assumption of diffusive equilibrium and the temperature profile below 200 $\mathrm{km}$ [Alcayde et al., 1974]. Figure 9 shows the result of this procedure in terms of the north-south difference in oxygen concentration at $200 \mathrm{~km}$. It is clear that the results at $45^{\circ}$ are dominated by seasonal effects essentially showing that the oxygen tends to be accumulated over the cold hemisphere (winter). This is in agreement with the results of previous studies [e.g., Evans et al., 1970; Barlier et al., 1971; Hedin et al., 1974; Alcaydé et al., 1974].

The $25^{\circ}$ results are quite different and definitely exhibit an asymmetry. Indeed, the $25^{\circ} \mathrm{N}$ concentrations are always larger than or equal to the $25^{\circ} \mathrm{S}$ concentrations. This is to be compared with the asymmetry in temperatures (Figure 1) and also tends to show that the atomic oxygen accumulates over the colder region.

A second feature can be deduced from the previous computations: a higher seasonal variability of the atomic oxygen concentration in the northern hemisphere than in the southern hemisphere. For this purpose the concentrations in local winter and local summer have been computed. Figure 10 shows the ratio of the above concentrations at 1700 hours local time for different latitudes. A greater variability appears in the northern hemisphere than in the southern hemisphere, contrary to the helium behavior. 

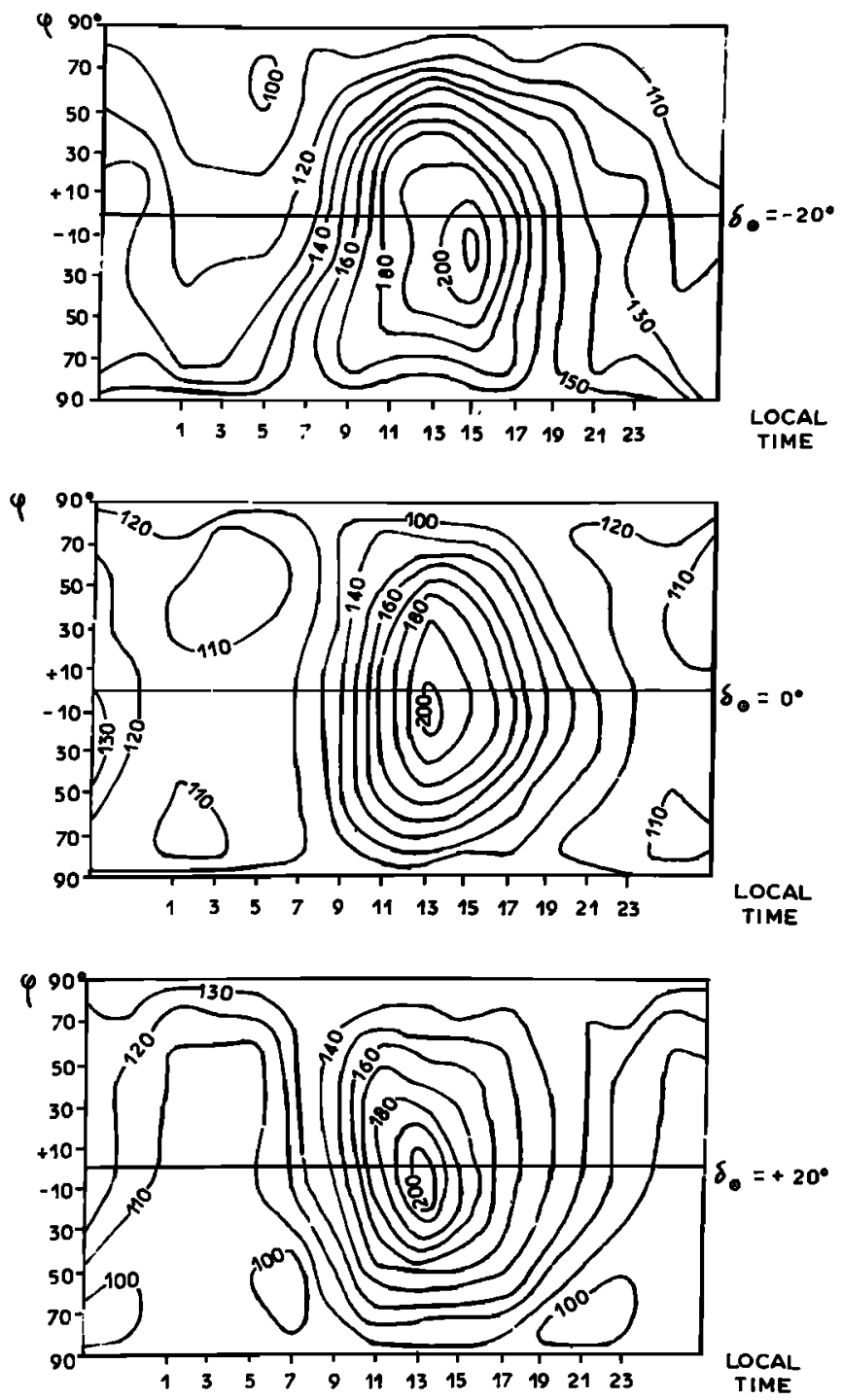

Fig. 7. Values of the ratio of observed densities and the nıghttime minimum density of the Jacchia 1971 model as a function of local solar time and latitude for time period centered around $\delta_{s}=$ $-20^{\circ}, 0^{\circ}$, and $+20^{\circ}$.

Neutral winds in the F region. Thuillier [1973] and Thuillier and Blamont [1973] have shown that the nighttime $6300-\AA$ emission observed on board Ogo 4 and 6 in the tropical regions can be interpreted in terms of thermospheric winds. Owing to the role of the magnetic field declination it appears that the region $0^{\circ}-150^{\circ} \mathrm{E}$ is convenient for the study of meridional winds across the equator. The small declination of the magnetic field in this region renders negligible the effect of zonal wind in the behavior of the $6300-\AA$ emission.

The tropical emission north of the magnetic equator in January has been compared with the southern data in June (Figure 11). The intensity variation is due to the altitude change of the $F$ layer, and it is possible to conclude that for part of the night the meridional wind blowing from the south toward the north in January is greater than the one blowing from the north toward the south in June (Figure 11). This experimental result is compatible with the hypotheses used by Keating et al. [1973] to interpret the helium distribution.

A transequatorial wind blowing from the summer to the winter hemisphere modifies the altitude of the $F$ layer, as has been described by Bramley and Young [1968]. Without the wind the $h_{m} F_{2}$ distribution is symmetrical with respect to the magnetic dip equator. An asymmetry arises when a wind is blowing: in the summer hemisphere the $F$ layer rises in height, and in the winter hemisphere the $F$ layer falls. The result is the appearance of a maximum of $h_{m} F_{2}$ in the summer hemisphere and a minimum in the winter hemisphere.

The Comité Consultatif International des Radiotélécommunications (CCIR) predictions [Union Internationale des Télécommunications, 1967] contain an important volume of ionospheric data. When the corrections pointed out by J. W. King and G. Thuillier (private communication, 1974) are taken into account, the ionospheric behavior is obtained for different local times and seasons. Figure 12 shows the two belts of extreme $h_{m} F_{2}$ obtained for a constant local time from the data of the CCIR predictions. The complete set of those maps leads to the behavior of the minimum and maximum $h_{m} F_{2}$, designated as $h_{\mathrm{m} / \mathrm{n}}\left(h_{m} F_{2}\right)$ and $h_{\max }\left(h_{m} F_{2}\right)$, respectively. Figure 13 compares the results for June and December 1967 and exhibits the following characteristics:

1. In Figure $13 a, h_{\mathrm{max}}\left(h_{m} F_{2}\right)$ is greater in December than in June.

2. In Figure $13 b, h_{\mathrm{min}}\left(h_{m} F_{2}\right)$ is comparable in June and December. The two local time variations are, however, not similar.

3. In Figure $13 c$ the difference $\Delta=\left[h_{\max }\left(h_{m} F_{2}\right)-\right.$ $\left.h_{\mathrm{min}}\left(h_{m} F_{2}\right)\right] / 2$ is plotted versus local time. It is seen that $\Delta$ is higher in December than in June and is different in phase.

4. In Figure $13 d$ the sum $S=\left[h_{\max }\left(h_{m} F_{2}\right)+h_{\min }\left(h_{m} F_{2}\right)\right] / 2$ is plotted versus local time; $S$ represents a mean altitude of the $F$ layer that is higher in December than in June.

According to the theoretical results of Bramley and Young [1968] it appears that the meridional wind blowing from south to north in December is characterized by a higher speed than the wind blowing from north to south in June (property 3 ).

At the beginning of the night the $F$ layer is higher in December than in June, and this situation remains throughout the night. Therefore during the daytime the eastward electric field, which causes the $F$ layer to rise, must be larger in December than in June (property 4).

Thus the behavior of the $F$ region is not symmetrical in June and December and exhibits an annual component.

Lower thermosphere sodium concentrations. It is well known that the sodium concentration at $85 \mathrm{~km}$ undergoes a seasonal variation [Donahue and Blamont, 1961; Gadsden, 1964; Gault and Rundle, 1969]. Maximums of concentration have been observed during the local winter for both hemispheres. Unfortunately, it is difficult to compare the values obtained by different authors because of intercalibration problems of the photometers. It seems, however, that the concentration of sodium is higher in December over the northern hemisphere and that the variability of the concentration is higher in the north (Table 1). It is still an asymmetrical characteristic. The seasonal behavior is similar to that of atomic oxygen at $200 \mathrm{~km}$ (Figure 9): in particular, the variability seems higher in the northern hemisphere than in the southern hemisphere.

\section{TENTATIVE INTERPRETATION}

The preceding data show that annual variations in addition to seasonal changes are present in the thermosphere. Two annual components must be considered: the first component is independent of latitude, and the second component responsible for the asymmetry is a function of latitude.

Possible sources of latitude independent components. 

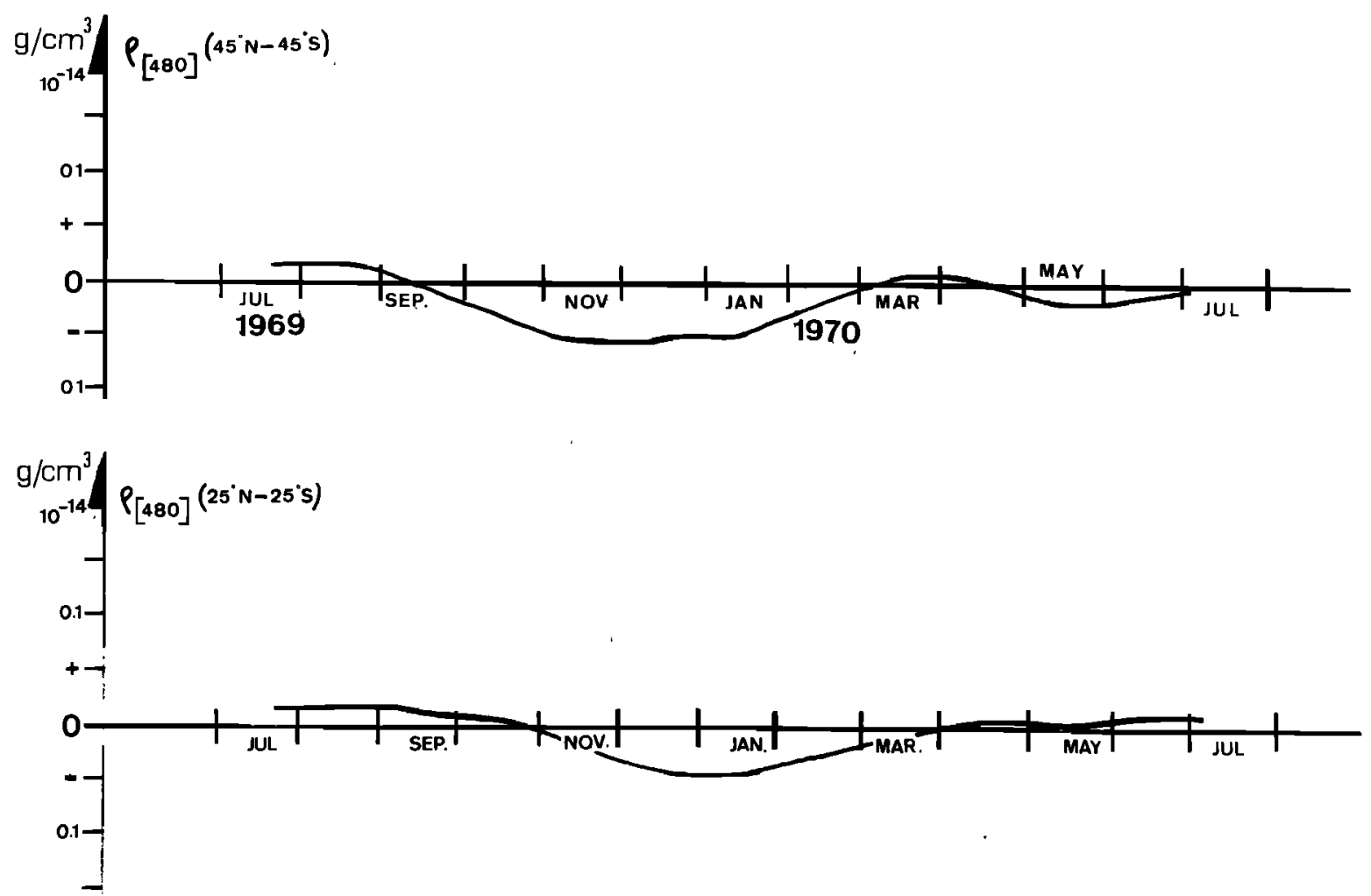

Fig. 8. Difference between northern hemisphere and southern hemisphere densittes at $480 \mathrm{~km}$, deduced from statistical analysis, for the same period and geometrical position as the Ogo 6 temperature measurements.

Several studies of possible sources of latitude independent components have been made, and several processes can be involved:

1. Extreme ultraviolet heating in the thermosphere linked to the changing sun-earth distance [Ching and Chiu, 1972, 1973].
2. Tidal and gravity wave dissipation at thermospheric heights whose efficiency is also a function of the sun-earth geometry and of the absorption of solar radiation within the ozone layer [Volland et al., 1972].

3. Joule heating depending on the geomagnetic activity [Ching and Chiu, 1973; Volland et al., 1972].

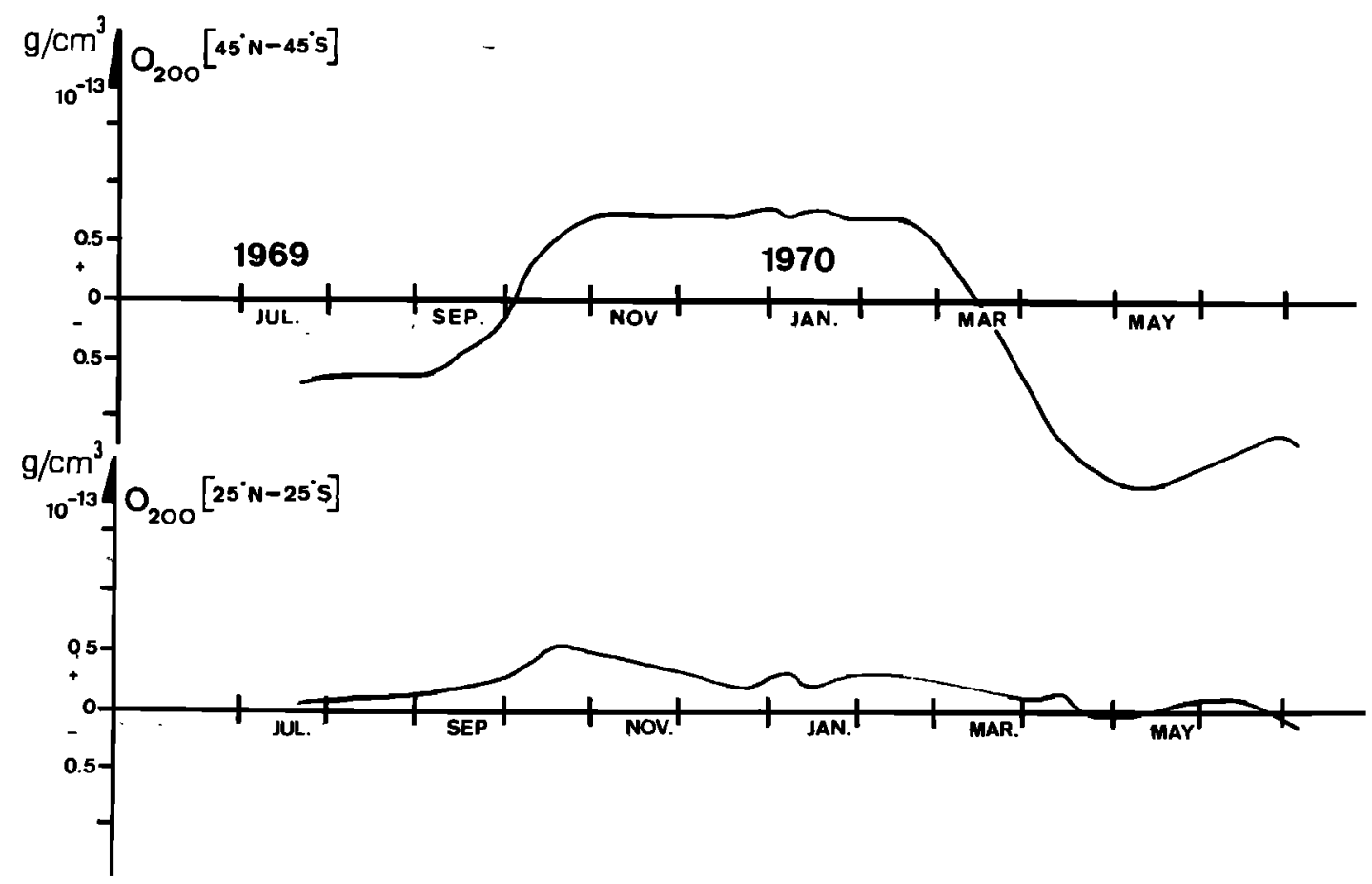

Fig. 9. Difference between northern hemisphere and southern hemisphere atomic oxygen densities at $200 \mathrm{~km}$ deduced from observed densities and temperatures. 


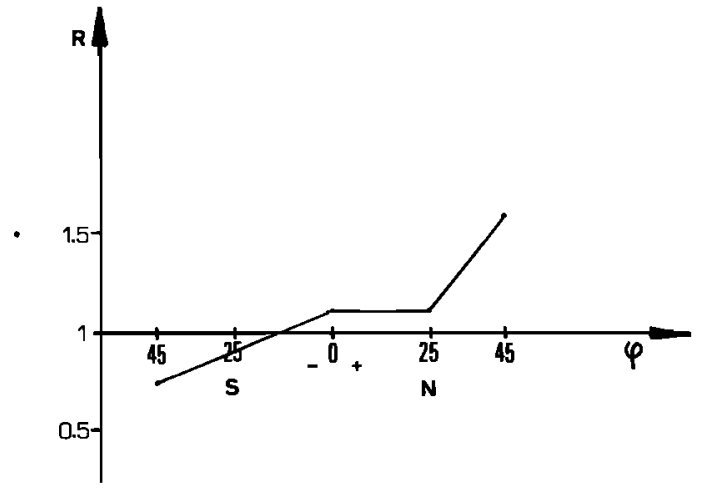

Fig. 10. Ratio $R=[O]_{200}$ December $1969 /[O]_{200}$ June 1969 for different latitudes.

Search for a source of asymmetry yielding a latitude dependent component. It is important to note that in calculating the action of the sun on the two hemispheres, account must be taken of the fact that the asymmetries persist at the equinox. The following hypothesis can be put forward: for comparable solar conditions (equal and opposite declinations of the sun and the same solar activity) the southern hemisphere is able to gather more energy than the northern hemisphere (particularly at equinox).

The effects of the preceding hypothesis are now analyzed in more detail.

Effect of the temperature. The first consequence of an unbalanced efficiency of the solar effect in the thermosphere between the two hemispheres is a generally higher worldwide exospheric temperature for the solstice that corresponds to the highest sun-atmosphere interaction (i.e., the December solstice).

Thus an annual variation must be added to the seasonal variation: in phase in the south and out of phase in the north. In this instance the small temperature variation observed in the north and the large one observed in the south should be noted (Figure 5). Furthermore, the fact that Waldteufel and Cogger [1971] did not observe any significant seasonal variation of the temperature above Arecibo $\left(18^{\circ} \mathrm{N}\right)$ proves that there is an exact cancellation of the seasonal and annual variations at that latitude. The proposed mechanism suggests mainly that for both equinoxes the southern hemisphere must be warmer than the northern hemisphere. This is in agreement with the features shown in Figure 1.

Effect on the thermospheric density. Owing to the thermal expansion the density bulge is expected to have a tendency to stay in the southern hemisphere. This tendency is actually observed (Figure 7). It is also expected that the larger annual temperature variation of the southern middle-latitude thermosphere with respect to the northern one also causes larger annual changes in density, as is observed (Figure 7).

Effect on the circulation. The temperature and density buildup in the southern hemisphere leads to pressure maps capable of causing, in addition to the normal seasonal circulation, a wind system blowing from south to north that corresponds to the optical observations (Figure 11) and to the ionospheric data (Figure 12).

Effect on the composition. Johnson and Gottlieb [1970,. 1973], Johnson [1973], and Reber and Hays [1973] have shown that a meridional circulation tends to accumulate the light constituents (as compared with molecular nitrogen) in the region of converging winds (pressure minimums) and to deplete the heavy constituents (as compared with $\mathrm{N}_{2}$ ) in the same region. In addition to the seasonal changes resulting for such a mechanism there will be an accumulation of the light gases over the northern hemisphere as a result of the south to north wind system. Such behavior is observed in the atomic oxygen concentration reduced at $200 \mathrm{~km}$ (Figure 9) as well as in the helium concentration (Figure 6). There is a puzzling feature that is difficult to describe with the previous mechanism; i.e., the largest seasonal variability appears in the southern hemisphere for helium (Figure 6), whereas it occurs in the northern hemisphere for atomic oxygen (Figure 10).

This point can be clarified by noting that a winter bulge can also be explained by a latitudinal variation of the eddy diffusion coefficient [Kockarts, 1972]. Furthermore, it has been shown [Kockarts. 1973] that the effect of a wind system on a vertical distribution can be represented by an appropriate eddy diffusion coefficient or vice versa. Circulation and turbulence should therefore play a simultaneous and complementary role in the structure of the upper atmosphere. An illustration of the possible effect of turbulence is given in Figure 14, where the helium concentration at $400 \mathrm{~km}$ is plotted as a function of an altitude independent eddy diffusion coefficient adopted above $90-\mathrm{km}$ height. When the entire variation of helium deduced by Keating et al. [1973] is assumed to result from turbulence effects between 90 and $120 \mathrm{~km}$, the required latitudinal and seasonal dependence of the eddy diffusion coefficient is shown in Figure 15. These values should be considered as orders of magnitude, since the vertical structure of the eddy diffusion coefficient has been neglected.

With the available data from chemical tracers on turbulence above $90 \mathrm{~km}$ [Lloyd et al., 1972; Philbrick et al., 1973a] it is

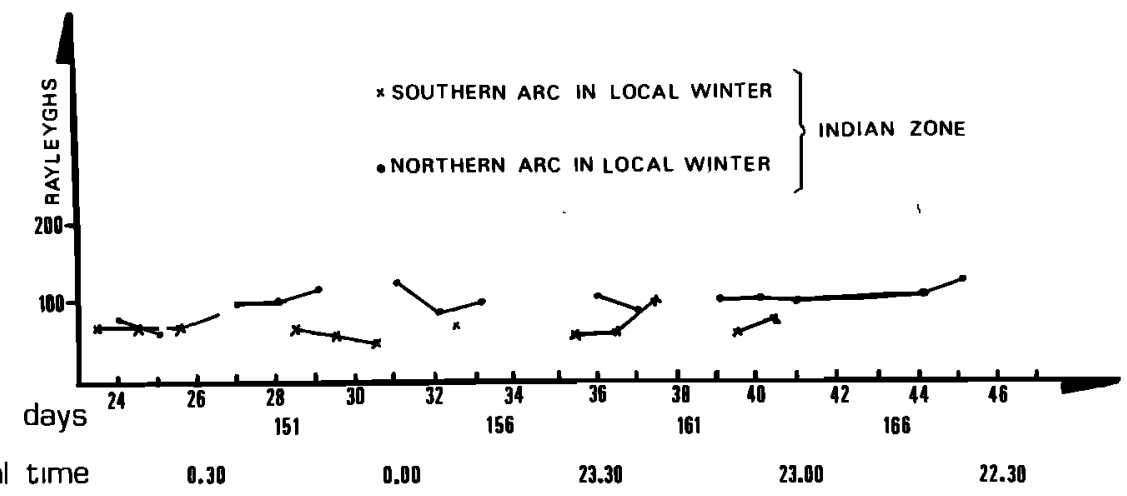

Fig. 11. Comparison of the intensity of the northern arc in December (local winter) with that of the southern arc in June (local winter). 


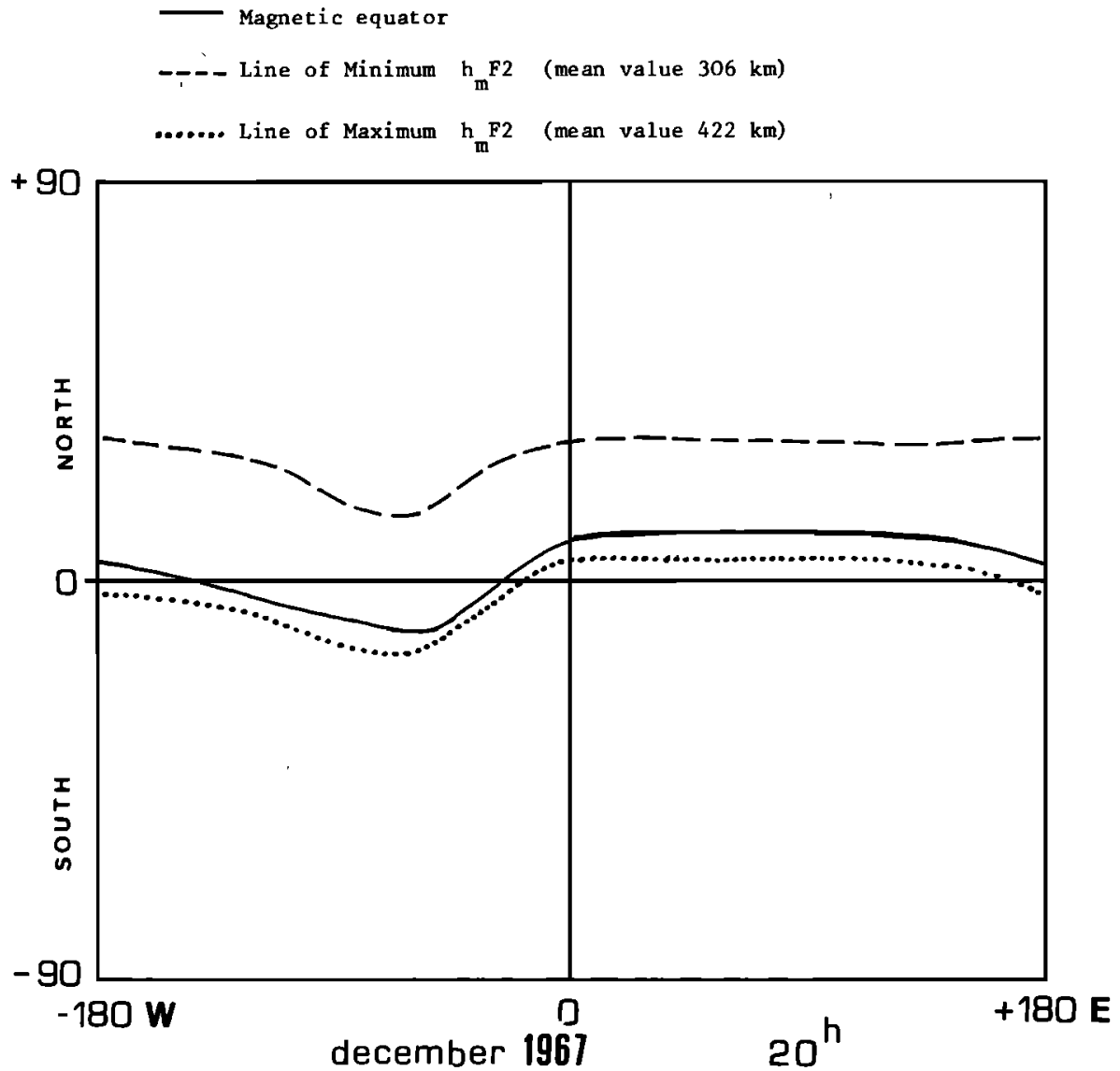

Fig. 12. The two belts of maximum and minimum $h_{m} F_{2}$ for December 1967.

very difficult to build a global model of the latitudinal and seasonal variations [Roper, 1973]. Radio meteor trails are also used to measure the atmospheric turbulence [Zimmerman. 1973]. Although the experimental data do not cover sufficiently well all latitudes and seasons, the theoretical computations of Figure 15 indicate that the world average value of the eddy diffusion coefficient is higher during December than during June.

The similarity in the northern and southern winter helium bulges can now be explained. The wind system (south-north) is more intense in the northern winter (December) than in the southern winter (June) because of the asymmetry in the meridional circulation. Therefore the winter helium bulge should be larger in the north than in the south. But the world average turbulence is higher in December than in June (Figure $15)$, so that the northern winter bulge is not as large as is predicted from the meridional circulation and finally, the winter bulges are similar in the two hemispheres.

The situation is not the same for the summer helium depletion. For the southern summer both the higher turbulence in December and the south-north wind produce a reduction of the helium concentration. Therefore the depletion is larger in the south than in the north, explaining the difference in the winter-summer variability between the two hemispheres.

One may wonder then why the same feature is not observed in the behavior of the atomic oxygen concentration. Keneshea and Zimmerman [1970] showed that an increase in the turbulence has two opposite effects on the atomic oxygen concentration: the first is to increase the production of $O$ following the increase of $\mathrm{O}_{2}$ around $120 \mathrm{~km}$ and the second is to increase the rate of downward diffusion of $\mathrm{O}$ into the region where it is recombined. The two effects seem to lead to a situation in which for an increased turbulence the atomic oxygen concentration above the peak remains unchanged, whereas that below it is smaller. The experimental data of Philbrick et $a l$. $[1973 b]$ seem to confirm the above theoretical work. Thus the variability is linked more closely to the winds than to the turbulence and will be higher in the north than in the south, as has been indicated in Figure 10. It should be mentioned that any theoretical study of the latitudinal and seasonal variation of atomic oxygen should take into account the variations of the molecular oxygen photodissociation coefficient with the solar zenith distance. An explanation of this kind may be valuable for sodium but has not yet been developed.

In conclusion, by assuming that greater energy is kept in the southern thermosphere than in the northern thermosphere for the same solar conditions a satisfactory understanding of the asymmetries described previously can be obtained. We had to assume, however, that the world average turbulence is higher in December than in June.

\section{Possible Nature of Sources}

The physical characteristics analyzed in the preceding sections should be related to thermospheric heat sources that are asymmetrical even during the equinoxes. Therefore the effects linked to the geomagnetic activity will be considered, because the geomagnetic field of the earth exhibits a permanent asymmetry at high latitudes as well as at low latitudes (South Atlantic anomaly). The tidal wave dissipation will also be studied, since the atmosphere below the thermosphere presents some asymmetrical aspects. Finally, other sources already known must be considered for a global understanding; in par- 

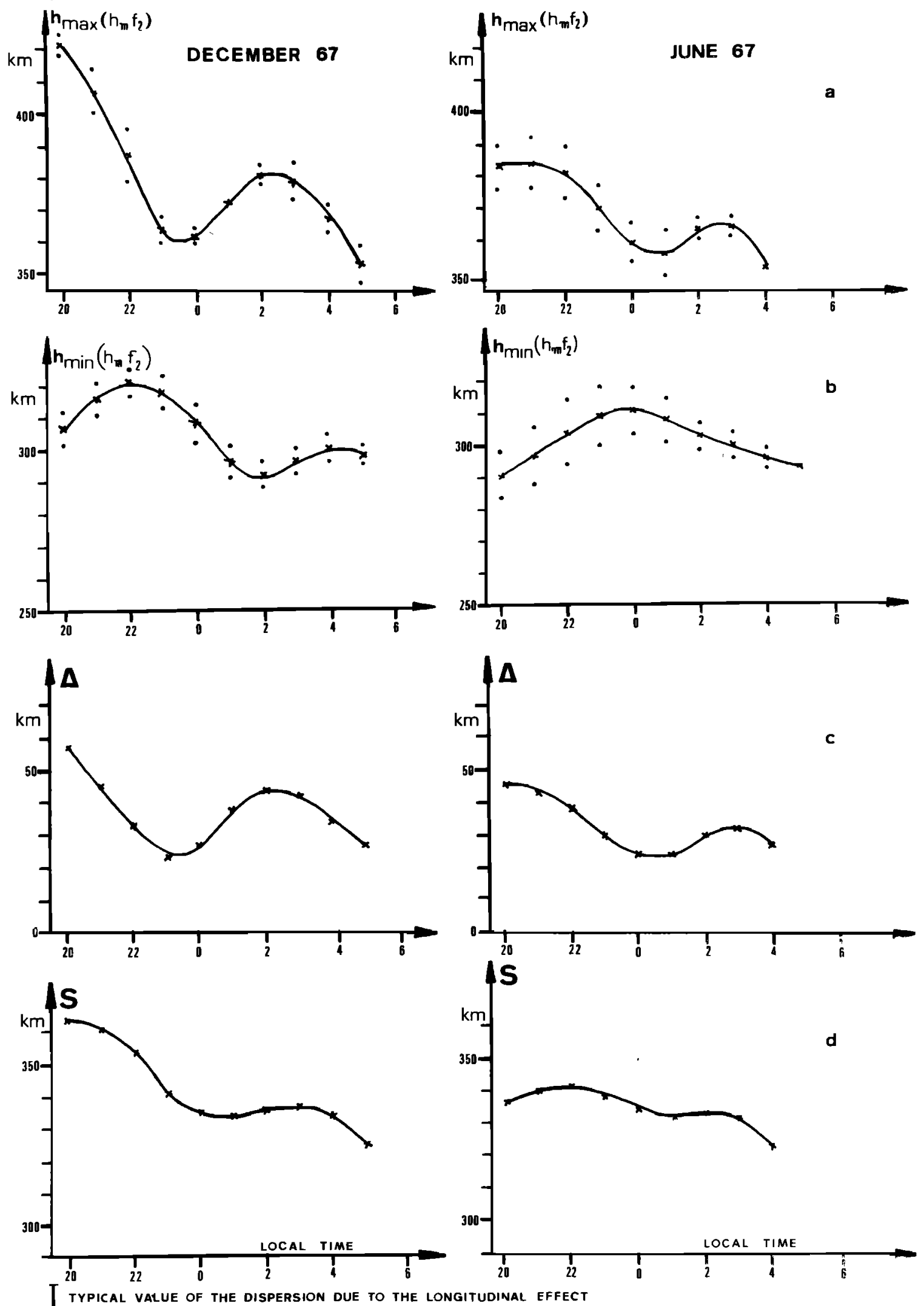

Fig. 13. Comparison of the maximum and minımum altutude of the $F_{2}$ layer for June and December 1967. 
TABLE 1. Seasonal Variation of Sodium Concentrations in the Lower Thermosphere

\begin{tabular}{lcccc}
\hline Author & Year & $\begin{array}{c}\text { Geographical } \\
\text { Location }\end{array}$ & $\begin{array}{l}\text { Na Concentrations, } \mathrm{cm}^{-3} \\
\text { Winter }\end{array}$ & $\begin{array}{l}\text { Local } \\
\text { Summer }\end{array}$ \\
\hline Gadsden & 1962 to 1963 & $\begin{array}{c}\text { Lauder } \\
-45^{\circ} \mathrm{S}, 169^{\circ} \mathrm{E} \\
\text { Haute-Provence } \\
\text { Observatory } \\
+44^{\circ} \mathrm{N}, 6^{\circ} \mathrm{E}\end{array}$ & $14 \times 10^{9}$ & $1.5 \times 10^{9}$ \\
\hline
\end{tabular}

ticular, the changing earth-sun distance must be taken into account.

Effects linked to the geomagnetic activity. The importance of heating processes connected to geomagnetic activity has been pointed out even for quiet periods [Blamont and Luton. 1972]. In a recent paper, Torr and Torr [1973] have also shown the importance of the effects in latitude and longitude linked to geomagnetic activity for an understanding of the winter $F$ region anomaly, which is another aspect of the general asymmetries. These authors conclude that globally, the southern hemisphere receives more energy than the northern hemisphere, and they point out a particular geomagnetic effect in the south. It therefore appears that asymmetries can be introduced through the geomagnetic activity even during the equinoxes. However, this sole source could not explain the greater variability of the exospheric temperature in the southern thermosphere. Other heat sources are important; for example, EUV heating variations linked to the changing earth- sun distance must be considered, introducing an annual component.

Unbalanced excitation of tides. Since the need for a higher worldwide turbulence in December has been noticed and since turbulence is linked to energy deposited in the mesosphere and propagating upward, possible tidal effects should be considered.

It has been suggested that the energy dissipation of semidiurnal tides in the thermosphere is sufficient to account for the difference between the observed temperatures and those computed theoretically [Roble and Dickinson, 1973] on the basis of EUV solar fluxes measured by Hinteregger [1970]. Lindzen and Blake [1970] give an order of magnitude of $0.3 \mathrm{erg}$ $\mathrm{cm}^{-2} \mathrm{~s}^{-1}$ deposited above $150 \mathrm{~km}$, compared with the daily average of $0.5 \mathrm{erg} \mathrm{cm}^{-2} \mathrm{~s}^{-1}$ for the EUV heating. Some support for this theoretical work is given by recent wind measurements in the $100-$ to $200-\mathrm{km}$ range, exhibiting semidiurnal tides, made by Bernard and Spizzichino [1971], Amayenc [1974], Ber-

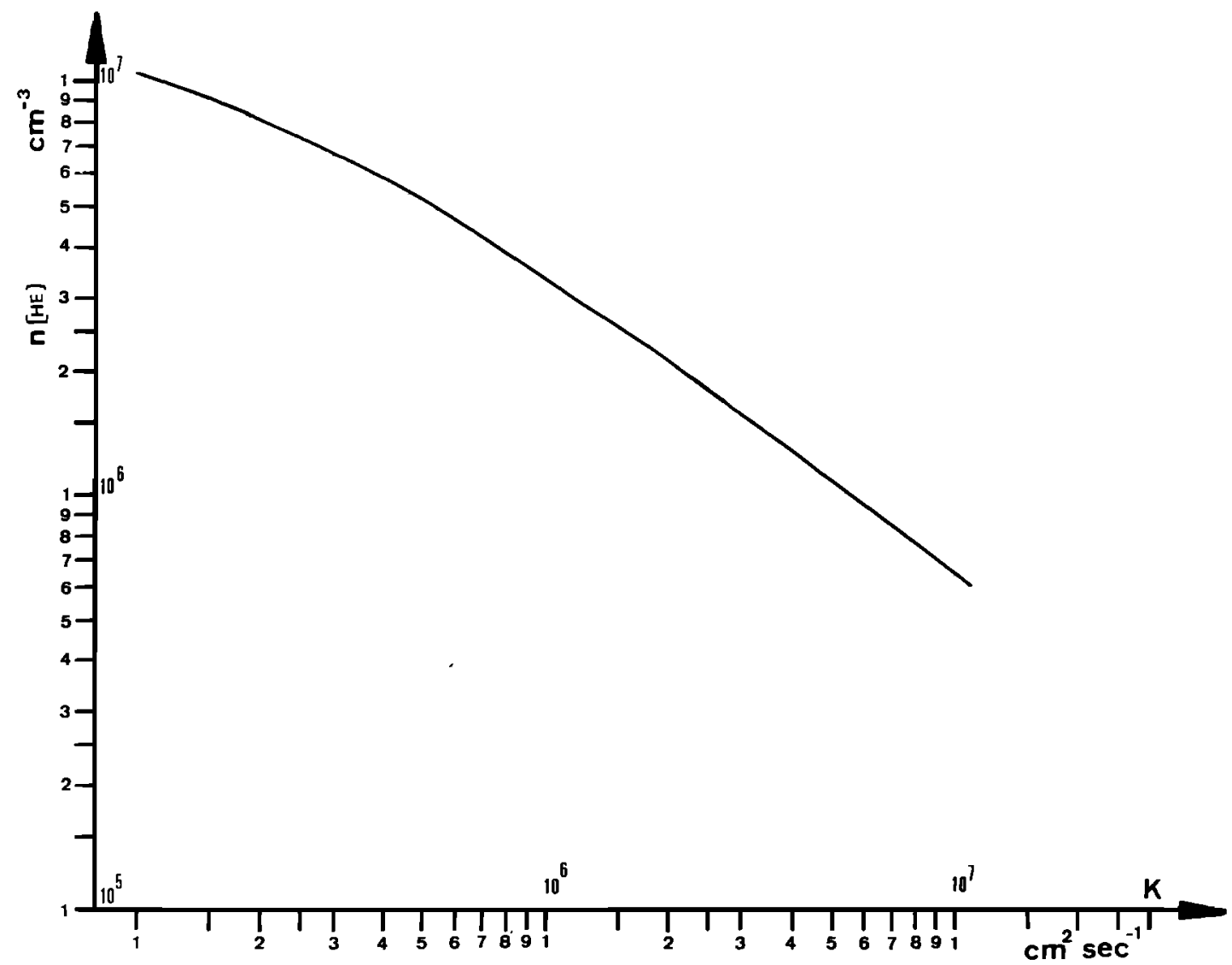

Fig. 14. Helium concentration at $400 \mathrm{~km}$ as a function of an altitude independent eddy diffusion coefficient adopted above $90-\mathrm{km}$ height. 


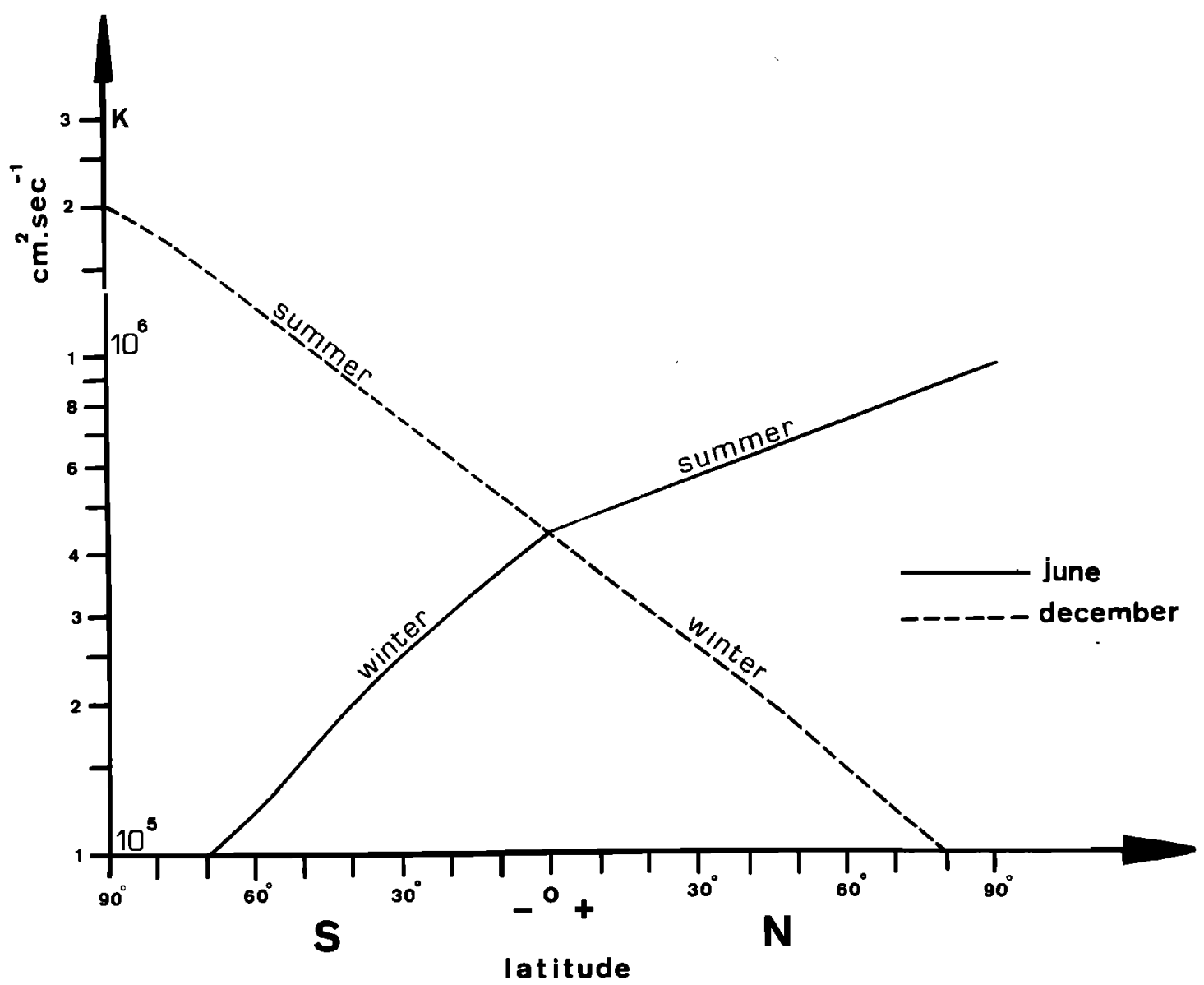

Fig. 15. Latitudinal and seasonal dependence of the eddy diffusion coefficient when the entire variation of helium deduced by Keating et al. [1973] is assumed to result from the turbulence effect between 90 and $120 \mathrm{~km}$.

nard [1974] at St. Santin, Wand [1972], and Salah and Evans [1973].

For the St. Santin results it should be noted that the amplitudes observed for the semidiurnal tide seem to indicate an annual trend with a maximum centered around December. One might wonder whether this characterizes a local seasonal variation or a larger worldwide excitation of the semidiurnal tides during the December solstice. Although all the equipment allowing this kind of observation is located in the northern hemisphere, making it impossible to distinguish between annual and seasonal variations, the convergence of the evidence is sufficiently strong to consider an asymmetry in the semidiurnal tide excitation between the solstices as a possible mechanism.

Before examining the source of the semidiurnal tide it is interesting to indicate that the equatorial electrojet [Mayaud, 1967] as observed in Jarvis $\left(160^{\circ} \mathrm{W}, 0^{\circ}\right)$, where the magnetic and geographical equators coincide, shows a definite annual variation with higher intensities in December than in June. Since the electrojet is driven by tidal motions, this seems also to confirm the higher tidal intensity in December.

Atmospheric ozone. It is known [Butler and Small, 1963; Lindzen, 1966, 1967; Chapman and Lindzen. 1970] that the source of semidiurnal tides is to be found in the ozone layer.

Therefore an asymmetrical tidal dissipation should be correlated with an asymmetry in the ozone distribution between the two hemispheres. Glass [1973] studied the effect of ozone distribution on the energy deposited by tides in the mesosphere. From these computations it appears that the tidal energy input increases with the ozone concentration. More specifically, an increase of the total ozone content leads to an increase of the tidal energy dissipation when the absolute value of the vertical ozone gradient is increased in the mesosphere. An analysis of the worldwide effect based on realistic ozone distributions has not yet been made. Such a study would require, however, a knowledge of global ozone distributions up to mesospheric levels.

Numerous studies of tropospheric and stratospheric ozone have been based on the indirect 'Umkehr' method and on direct soundings [Dütsch, 1970, 1971]. There exists a definite latitudinal and seasonal asymmetry between both hemispheres, although some details are not completely documented owing to the small number of stations in the network in the southern hemisphere. From these data it appears, however, that the seasonal variation is less pronounced in the south and that the maximum of the total content occurs closer to mid-latitudes in the south than in the north. During late local summer, autumn, and early winter there is more ozone over mid-latitudes in the southern hemisphere than in the northern hemisphere [Kulkarni, 1962].

Satellite measurements of the backscattered ultraviolet earth radiance [Krueger et al., 1973] as well as infrared in: terferometric data [Prabhakara et al., 1973] should give a better world coverage between $80^{\circ} \mathrm{N}$ and $80^{\circ} \mathrm{S}$ for the total ozone content and for the vertical distribution up to approximately $50 \mathrm{~km}$. There are, however, not yet enough data 
to obtain a global picture of mesospheric ozone, although nighttime profiles can now be obtained from satellite measurements of the intensity of ultraviolet stars during occultation by the earth's atmosphere [Hays and Roble, 1973].

Although the asymmetrical behavior of ozone is rather complicated, it is worthwhile to investigate its effect on the tidal energy input in the upper atmosphere.

\section{Conclusion}

An asymmetrical behavior of the northern and southern thermospheres has been demonstrated with the aid of several types of experimental data. It seems well established that more energy must be deposited in the southern thermosphere than in the northern thermosphere, even during the equinoxes. The origin of this fact is not completely clear, but two mechanisms can be considered, namely, the geomagnetic field asymmetry and the tidal wave dissipation, linked to the asymmetrical worldwide ozone distribution.

Acknowledgments. We would like to thank J. E. Blamont and J. $M$. Luton for giving us temperature data and P. Waldteufel for giving us his temperature model. We are very grateful to $\mathbf{M}$. Glass for several discussions and to Diane Perret, who started this study and whose results were largely used in this work.

The Editor thanks L. G. Jacchia and another referee for their assistance in evaluating this paper.

\section{REFERENCES}

Alcaydé, D., P. Bauer, and J. Fontanari, Long-term variations of the thermospheric temperature and composition, J. Geophys. Res., 79, 629, 1974.

Amayenc, P., Tidal oscillations of the meridional neutral wind at midlatitudes, Radio Sci., 9, 281, 1974.

Barlier, F., D. Perret, and C. Jaeck, Seasonal variation of the atomic oxygen concentration in the lower thermosphere, J. Geophys. Res., $76,7797,1971$.

Barlier, F., J. L. Falin, M. III, and C. Jaeck, Structure of the neutral atmosphere between 150 and $500 \mathrm{~km}$, Space Res., 13, 349, 1973.

Bernard, R., A comparison between meteoric radar and incoherent scatter measurements in the lower thermosphere, Radio Sci., 9. 295, 1974.

Bernard, R., and A. Spizzichino, Semi-diurnal wind and temperature oscillations in the $E$-region observed by the Nancay incoherent scatter experiment, J. Atmos. Terr. Phys., 33, 1345, 1971.

Blamont, J. E., and J. M. Luton, Ogo 6 neutral temperature measurements, Comparison with the temperature models, 114 pp., COSPAR, Seattle, Wash., 1971.

Blamont, J. E., and J. M. Luton, Geomagnetic effect on the neutral temperature of the $F$ region during the magnetic storm of September 1969, J Geophys. Res., 77, 3534, 1972.

Bramley, E. N., and M. Young, Winds and electromagnetic drifts in the equatorial $F 2$ region, J. Atmos. Terr. Phys., 30, 99, 1968.

Butler, S. T., and K. A. Small, The excitation of atmospheric oscillations, Proc. Roy. Soc. London, Ser. A, 274, 91, 1963.

Chapman, S., and R. S. Lindzen, Atmospheric Tides, p. 120, D. Reidel, Dordrecht, Netherlands, 1970.

Ching, B. K., and Y. T. Chiu, Annual and sub-annual effects of a EUV heating, 1, Harmonic analysis, 2, Comparison with density variations, Planet. Space Sci., 20, 1745, 1972.

Ching, B. K., and Y. T. Chiu, Global distribution of thermospheric heat sources: EUV absorption and Joule dissipation, Planet. Space Sci., 21, 1633, 1973.

Donahue, T. M., and J. E. Blamont, Sodium in the upper atmosphere, Ann. Geophys., 17, 116, 1961.

Dütsch, H. U., Atmospheric ozone, A short review, J. Geophys. Res., $75,1707,1970$.

Dütsch, H. U., Photochemistry of atmospheric ozone, in Advances in Geophysics, vol. 15, edited by H. E. Landsberg and J. Van Mieghem, pp. 219-322, Academic, New York, 1971.

Evans, J. V., and L. P. Cox, Seasonal variation of the $F_{1}$ region ion composition, J. Geophys. Res., 75, 159, 1970.
Gadsden, M., On the twilight sodium emission, 2, A theoretical model of sodium abundance, Ann. Geophys., 20, 383, 1964.

Gault, W. A., and H. N. Rundle, Twilight observations of upper atmospheric sodium, potassium and lithium, Can. J. Phys., 47, 85, 1969.

Glass, M., Etude des limites temporelles des ondes de gravité observées dans la basse thermosphère, Ph.D. thesis, Unıv. de Paris, Paris, 1973.

Harper, R. M., Ph.D. thesis, Rice Univ., Houston, Tex., 1971.

Hays, P. B., and R. G. Roble, Observation of mesospheric ozone at low latitudes, Planet. Space Sci., 21, 273, 1973.

Hedin, A. E., H. G. Mayr, C. A. Reber, N. W. Spencer, and G. R. Carignan, Empirical model of global thermospheric temperature and composition based on data from the Ogo 6 quadrupole spectrometer, J. Geophys. Res., 79, 215, 1974.

Hinteregger, H. E., The extreme ultra violet solar spectrum and its variation during a solar cycle, Ann. Geophys., 26, 547, 1970.

Jacchia, L. G. The temperature above the thermopause, Space Res., 5 , $1152,1965$.

Jacchia, L. G., Semiannual variation in the heterosphere, A reappraisal, J. Geophys. Res., 76. 4602, 1971 a.

Jacchia, L. G., Revised static models of the thermosphere and exosphere with empirical temperature profiles, Spec. Rep. 332, 115 pp., Smithson. Astrophys. Observ., Cambridge, Mass., $1971 b$.

Jaeck-Berger, C., Modèle statistique de densité globale entre 180 et 500 km, Ann. Geophys., 29, 547, 1973.

Johnson, F. S., Horizontal variations in thermospheric composition, Rev. Geophys. Space Phys., 3, 741, 1973.

Johnson, F. S., and B. Gottlieb, Eddy mixing and circulation at onospheric levels, Planet. Space Sci., 18, 1707, 1970.

Johnson, F. S., and B. Gottlieb, Atomic oxygen transport in the thermosphere, Planet. Space Sci., 21, 1001, 1973.

Keating, G. M., D. S. McDougal, E. J. Prior, and J. S. Levine, Northsouth asymmetry of the neutral exosphere, Space Res., 13, 327, 1973.

Keneshea, P. J., and S. P. Zimmerman, The effect of mixing upon atomic and molecular oxygen in the $70-170 \mathrm{~km}$ region of the atmosphere, J. Atmos. Sci., 27, 831, 1970.

Kockarts, G., Distribution of hydrogen and helium in the upper atmosphere, J. Atmos. Terr. Phys., 34, 1729, 1972.

Kockarts, G., Helium in the terrestrial atmosphere, Space Sci. Rev., 14, 723, 1973.

Krueger, A. J., D. F. Heath, and C. L. Mateer, Variations in the stratospheric ozone field inferred from Nimbus satellite observations, Pure Appl. Geophys., 106-108, 1254, 1973.

Kulkarni, R. N., Comparison of ozone variations and of its distribution with height over middle latitudes of the two hemispheres, Quart. J. Roy. Meteorol. Soc., 88, 522, 1962.

Lindzen, R. S., On the theory of the diurnal tide, Mon. Weather Rev., 94, $295,1966$.

Lindzen, R. S., Thermally driven diurnal tide in the atmosphere, Quart. J. Roy. Meteorol. Soc., 93, 18, 1967.

Lindzen, R. S., and D. Blake, Mean heating of the thermosphere by tides, J. Geophys. Res., 75, 6868, 1970.

Lloyd, K. H., C. H. Low, B. J. McAvanay, D. Rees, and R. G. Roper, Thermospheric observations combining chemical seeding and ground-based techniques, 1 , Winds, turbulence and the parameters of the neutral atmosphere, Planet. Space Sci., 20, 761, 1972.

Mayaud, $P$. N., Corrélation entre les variations journalières du champ magnétique terrestre sous l'électrojet équatorial et dans les régions avoisinantes, Ann. Geophys., 23, 387, 1967.

Paetzold, H. K., and H. Zschörner, The structure of the upper atmosphere and its variations after satellite observation, Space Res., 2. 958,1961 .

Philbrick, C. R., R. S. Narcisi, R. E. Good, H. S. Hoffman, T. J. Keneshea, M. A. Macleod, S. P. Zimmerman, and B. W. Reinisch, The Aladdin experiment, 2, Composition, Space Res., 13, 441, $1973 a$.

Philbrick, C. R., G. A. Faucher, and E. Trzcinski, Rocket measurements of mesospheric and lower thermospheric composition, Space Res., 13, 255, $1973 b$.

Prabhakara, C., E. B. Rodgers, and V. V. Salamonson, Remote sensing of the global distribution of total ozone and the inferred upper tropospheric circulation from Nimbus Irıs experiments, Pure Appl. Geophys., 106-108, 1226, 1973.

Reber, C. A., and P. B. Hays, Thermospheric wind effects on the distribution of helium and argon in the earth's upper atmosphere, $J$. Geophys. Res., 78. 2977, 1973. 
Roble, R. G., and R. E. Dickinson, Is there enough solar extreme ultraviolet radiation to maintain the global mean thermospheric temperature?, J. Geophys. Res., 78, 249, 1973.

Roemer, M., Die Dichte der Hochatmosphäre und ihre Variationen während der Phase abklingender Sonnenaktivität 1958-1962, Veroeff. Univ. Sternwarte Bonn 68, 114 pp., 1963.

Roper, R. G., The dynamics of the turbopause, paper presented at General Scientific Assembly, Int. Ass. of Geomagn. and Aeron., Kyoto, Japan, 1973.

Salah, J. E., and J. V. Evans, Measurements of thermospheric temperatures by incoherent scatter radar, Space Res., 13, 267, 1973.

Thuillier, G., Explication de l'émission tropicale $\lambda 6300 \AA$ de l'oxygène atomique: Mesures et théorie, Ph.D. thesis, Univ. de Paris, Paris, June 1973.

Thuillier, G., and J. E. Blamont, Vertical red line $6300 \AA ̊$ dıstribution and tropical nightglow morphology in quiet magnetic conditions, in Physics and Chemistry of the Upper Atmosphere, edited by B. M. McCormac, pp. 219-231, D. Reidel, Dordrecht, Netherlands, 1973.
Torr, M. R., and D. G. Torr, The seasonal behaviour of the $F_{2}$ layer of the ionosphere, J. Atmos. Terr. Phys., 35, 2237, 1973.

Union Internationale des Télécommunications, Rep. 340, 117 pp., Com. Consult. Int. des Radiotélécommunications, Geneva, 1967. Volland, H., C. Wulf-Mathies, and W. Priester, On the annual and semi-annual variations of the thermospheric density, J. Atmos. Terr. Phys., 34, 1053, 1972.

Waldteufel, P., Exospheric temperatures from rockets and incoherent scatter measurements, J. Geophys. Res., 76, 6990, 1971.

Waldteufel, P., and L. Cogger, Measurements of the neutral temperature at Arecibo, J. Geophys. Res., 76, 5322, 1971.

Wand, R. H., Observations of reversible heating by tides in the $E$ region, 120 pp., Union Radio Sci. Int., 1972.

Zimmerman, S. P., Meteor trails and atmospheric turbulence, $J$. Geophys. Res., 78, 3927, 1973.

(Received April 1, 1974; accepted August 30, 1974.) 